\title{
Microangiographic Study of Spinal Cord Injury and Myelopathy
}

\author{
H Shingu, MD, I. Kimura, MD, Y. Nasu, MD, A Shiotani, MD, \\ M. Oh-hama, MD, A. Hijioka, MD, J. Tanaka, MD \\ Department of Orthopaedic Surgery, San-in Rosai Hospital, Yonago-si, 683, \\ Japan, Division of Neuropathology, Institute of Neurological Sciences, Tottori \\ University School of Medicine, Yonago-si, 683, fapan.
}

\section{Summary}

Post-mortem microangiography has been performed in 12 patients with traumatic cervical cord injury, 2 patients with myelopathy, and one patient with posttraumatic syringomyelia.

Microangiography defined 4 zones in the injured spinal cord.

In traumatic injury, the size and extent of the non-filling area (Zone 1) was directly related to the injury force. Subsequently these areas became cavitated. Surrounding the non-filling area, widely extending areas demonstrated filling of capillaries but showed damaged neurons and axons (Zone 2). In the chronic stage, Zone 2 replaced by gliomesenchymal tissue. The capillaries in the gliomesenchymal scars revealed a distorted abnormal arrangement (Zone 3).

In a case with myelopathy, the hypervascular areas (Zone 4) were observed just around the chronically compressed area. The vascular increases were considered to be a reaction against chronic compression.

In a patient with post-traumatic syringomyelia, the vascular network of the posterior grey matter disappeared and the central arteries were distorted by the distending forces of the syrinx. The microangiographs suggested that vascular factors might play a significant role in original cavity formation; but in cavity extension, these factors were not primary.

Key words: Spinal cord injury; Microangiography; Myelopathy, Post-traumatic syringomyelia; Autopsy studies.

Regarding pathological studies of spinal cord injury, Wolman (1965), Bedbrook (1966), Kakulus (1976), Jellinger (1976), Kinoshita (1977) and others have reported on the pathology of traumatic spinal cord injury.

Microangiography can demonstrate alterations in the small blood vessels of the central nervous system. Turnbull (1966), Crock (1977), Mannen (1963) and others have showed microangiographs of the spinal cord from unselected cadavers. Studies on the microangiography of spinal cord lesions in man are lacking. 
We here report the post-mortem microangiographic studies that we have undertaken in traumatic spinal cord injury and myelopathy during the last 25 years.

\section{Materials and methods}

The study is based on 12 patients with traumatic injury of the cervical spinal cord, 2 with cervical myelopathies and 1 patient with post-traumatic syringomyelia (Table).

At the time of autopsy the femoral and subclavian arteries were catheterised. Two litres of normal saline with heparin were perfused through the catheters to prevent blood clotting. Five litres of $20 \%$ barium suspensions (Micropaque or Baritogen-sol) were injected under $150 \mathrm{mmHg}$ pressure, using the infusion pump.

The spinal cord with its roots and dural covering was removed, and was fixed in $10 \%$ buffered formalin for 1 week. After fixation, posteroanterior, lateral, and series $5 \mathrm{~mm}$ thick transverse section microangiographs were taken on Fuji high grain film with a Softex ESM type. Sections $5 \mathrm{~mm}$ thick were then prepared from each transverse section and stained with haematoxylin and eosin, Luxol-fast blue, trichrome, and Bodian stain.

The microangiographs of the injured tissues were compared with corresponding histopathological sections.

\section{Results}

Four zones were defined by microangiography and histopathology of the injured spinal cord.

Zone 1 (non-filling area): Necrosis of all elements including capillaries and neurons ensued. Subsequently, the middle part of the area softened and became cavitated.

Zone 2 (filling, neural damaged area): In the intermediate stage of traumatic injury around the non-filling area, widely extending areas demonstrated microangiographic filling of capillaries but showed damaged neurons and axons. In final stages, Zone 2 replaced by gliomesenchymal tissue.

Zone 3 (filling, gliar scar area): In the final stage of traumatic injury and myelopathy, the arteries of gliomesenchymal scars revealed a distorted abnormal arrangement. They were bent, thin and short.

Zone 4 (hypervascular area): In myelopathy, the hypervascular regions were observed around the compressed areas. The vascular increase was considered a reaction against gradual compression.

\section{Traumatic spinal cord injury}

The pathology of spinal cord contusions was graded in three consecutive stages (Jellinger 1976).

First stage: early stage of haemorrhage and necrosis. Two patients died within the first 7 days following spinal cord injury. The anterior spinal arteries were perfused in all our patients. In the experimental study, microangio- 
Table Profiles and clinical features of 15 cases

\begin{tabular}{|c|c|c|c|c|c|}
\hline Case & $\begin{array}{l}\text { Age at } \\
\text { injury }\end{array}$ & Sex & $\begin{array}{l}\text { Duration from } \\
\text { onset to death }\end{array}$ & Bony lesion & Neurological symptoms \\
\hline \multicolumn{6}{|c|}{ Traumatic cervical cord injuries } \\
\hline 1 & 50 & $\mathrm{M}$ & 6 days & C4.5 dislocation & Respiratory-quadriplegia \\
\hline 2 & 50 & $\mathbf{M}$ & 6 days & C4 5 Hyperanteflexion & C4 complete cord lesion \\
\hline 3 & 23 & $\mathrm{M}$ & 12 days & C4/5 dislocation & Respiratory-quadriplegia \\
\hline 4 & 28 & $M$ & 30 days & C4/5 dislocation & Respiratory-quadriplegia \\
\hline 5 & 62 & $M$ & 5 months & Hyperextension & C6 anterior cord syndrome \\
\hline 6 & 45 & $M$ & 6 months & Hyperextension & C4 complete cord lesion \\
\hline 7 & 51 & $M$ & 8 months & C5/6 dislocation & C5 complete cord lesion \\
\hline 8 & 34 & $\mathrm{~F}$ & 9 months & C6 fracture & C5 complete cord lesion \\
\hline 9 & 48 & $\mathrm{M}$ & 12 months & C5/6 dislocation & C6 complete cord lesion \\
\hline 10 & 57 & $\mathrm{M}$ & 15 months & C4 5 fracture & C3 subtotal cord lesion \\
\hline 11 & 37 & $M$ & 4 years & C5/6 dislocation & C5 complete cord lesion \\
\hline 12 & 50 & $M$ & 7 years & Hyperextension & C5 complete cord lesion \\
\hline \multicolumn{6}{|c|}{ Cervical myelopathies } \\
\hline 13 & 61 & $\mathrm{M}$ & 3 years & C4 $\sim 7$ OPLL & C4 incomplete cord lesion \\
\hline 14 & 68 & $\mathrm{~F}$ & 6 years & $\mathrm{RA}, \mathrm{C} 1 / 2$ subluxation & C2 incomplete cord lesion \\
\hline \multicolumn{6}{|c|}{ Post-traumatic syringomyelia } \\
\hline 15 & 33 & $M$ & 8 years & T3 fracture & T3 complete cord lesion \\
\hline
\end{tabular}

graphs within the first 48 hours after injury showed large collections of extravasate of barium suspension in the areas of damaged tissue in the central cord. But there was no extravasation in these perfused at 7 days.

The non-filling area (Zone 1) was proportional to the force of injury.

In severe injury, filling defects of intramedullary arteries were spread over a transverse section of the injured segment in which there were mechanical tissue disruptions, massive haemorrhage, highly developed oedema and ischaemic necrosis. Surrounding the non-filling areas, widely extending areas were Zone 2. A mixture of necrotic tissue, glial cells, macrophages, and damaged neurons were found along with swollen axons and multiple end retraction bulbs (Zone 2).

In a case of mild injury, the central arteries and the tree-like branches failed to fill for $5 \mathrm{~mm}$ length in the injured spinal cord.

Second stage: intermediate stage of resorption and organisation. Two patients died after 8 days to 1 month following spinal injury.

In a case of complete cord lesion, the anterior central arteries were not perfused in $30 \mathrm{~mm}$ length of the injured cord. In transverse section the massively ischaemic and intensely oedematous regions were shown as filling defects (Zone 1). The non-filling areas extended upwards and downwards in the form of a pencil involving as many as a dozen segments. It suggested that such extensive non-filling changes were possibly caused by ischaemia with disturbance of the venous outflow. The central part of the non-filling area was softened and became cavitated. In the areas around the filling-defect, capillary networks were well filled with contrast meda (Fig. 1), but glial cells, macrophages, damaged neurons and axons were observed histologically, and the large cells of the anterior horns were necrotic form C2 to C7 levels (Zone 2).

Third stage: final and defective stages. Eight patients died in the final stage. As time progressed, the damaged parts of the cord were replaced by gliomesenchymal tissue. The resolving necrotic areas became cavities, and were surrounded by vascularised granulation tissue which replaced the defect in a 


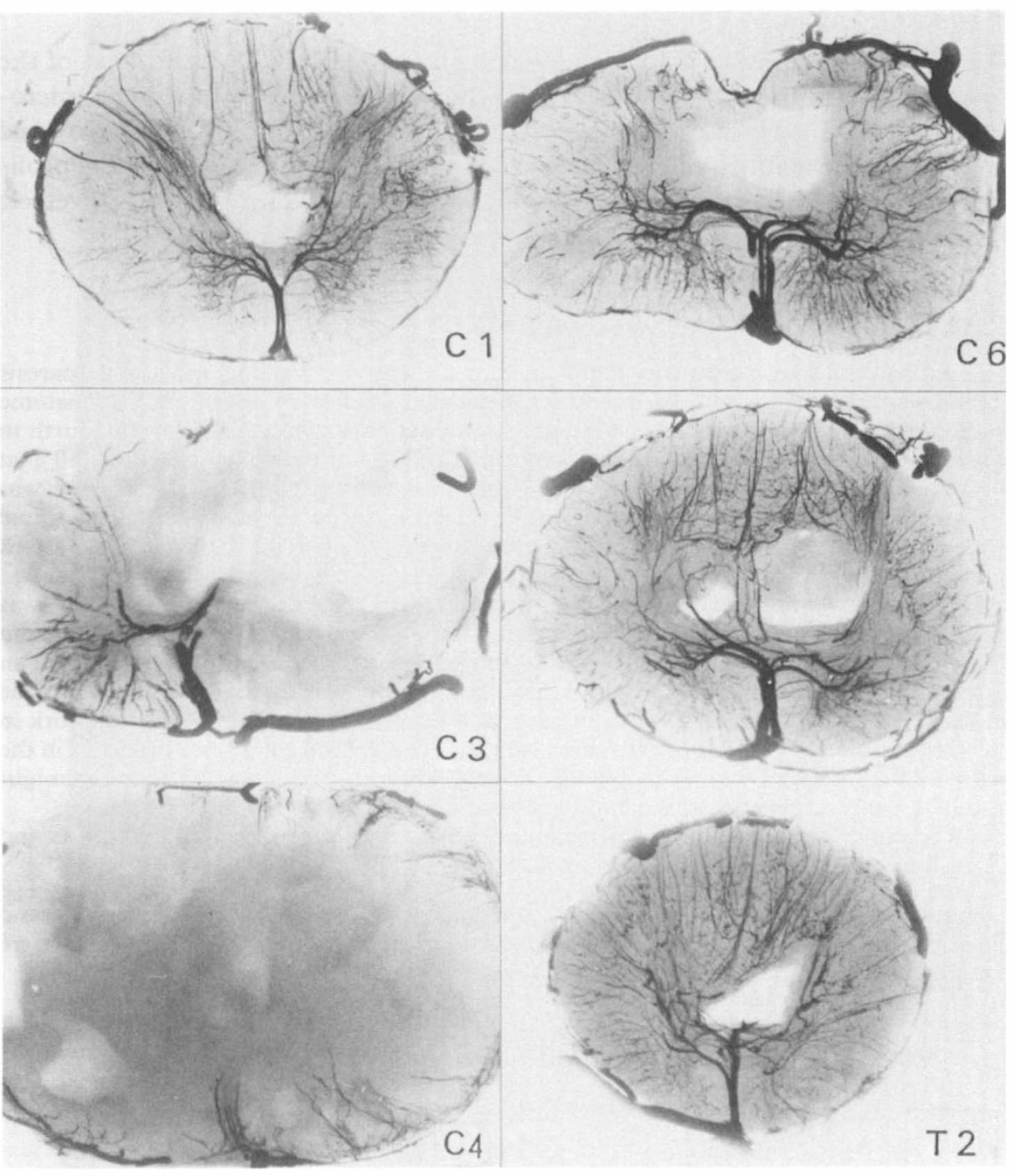

Figure 1 Case 4, 30 days after injury. Microangiograms of transverse section $5 \mathrm{~mm}$ thick. Nonfilling areas extend upwards $\mathrm{Cl}$ and downwards $\mathrm{T} 2$ in the form of a spindle involving in the central part of the cord (Zone 1).

centripetal direction and had included regenerated axis cylinders. The arteries in gliomesenchymal scars showed an irregular, short and abnormally distorting arrangement (Zone 3).

The anterior spinal artery was preserved in all cases including 1 patient with an anterior spinal cord syndrome.

Comment: In traumatic injury, the size and extent of the non-filling area was directly related to the injury force. Subsequently the central part of the nonfilling area softened forming cavities. Surrounding the non-filling area, widely extending areas demonstrated microangiographic filling of capillaries but showed damaged neurons and axons. 


\section{Myelopathy}

We observed 2 patients, who with myelopathy caused by the ossification of the posterior longitudinal ligament (OPLL) showed interesting findings on microangiography. In the other patient, with myelopathy caused by atlanto-axial subluxation in rheumatoid arthritis, a small focal necrotic lesion with glial proliferation was found and using microangiography the intramedullary small vessels appeared to be increased in number adjacent to the small cavities.

\section{Case 13: myelopathy caused by the OPLL}

The patient, a 61-year-old man, complained of difficulty in walking and spastic paresis was present in all four limbs with mild sensory deficits below the level of C5 dermatome in the upper extremities. Roentgenographic examination showed OPLL at the fourth to seventh levels of the cervical spine. The narrowing-ratio of the spinal canal was $50 \%$ at fourth cervical spine. Laminectomy from the third to the seventh cervical spine was performed. There was a mild dilation of the vessels on the posterior surface of the spinal cord. Despite clinical improvement following surgery, the patient died of a heart attack on the fortieth post-operative day.

Post-mortem microangiography demonstrated that the anterior spinal artery was patent. The central arteries and network branches in the grey matter was disrupted from $\mathrm{C} 4$ to $\mathrm{C} 8$, the normal vascular network disappeared and the intrinsic arteries showed an abnormal arrangement (Zone 3), although filling defects were seldom observed. In the flattened C7 and C8 segments, in contrast to a disappearance of the vascular network in the grey matter, the posterior perforating branches and central transverse branches in the white matters appeared to be increased (Zone 4) (Fig. 2). The vascular increase might be due to the reaction against the long-standing localised compression of the cord.

Microscopically, the pathological changes consisted of severe neuronal necrosis and demyelination with glial proliferation in $\mathrm{C} 4$ to $\mathrm{C} 6$.

Comment: In a patient with myelopathy, the normal vascular networks disappeared and the intrinsic arteries showed an abnormal arrangement, although fillings defects were seldom observed. The hypervascular areas were seen just around the compressed area.

\section{Post-traumatic syringomyelia}

Post-traumatic syringomyelia was found in case 15 at autopsy.

\section{Case 15}

The patient, a 33-year-old man, sustained a bursting fracture of $\mathrm{T} 3$ resulting in complete paraplegia. An intrathecal injection of alcohol was performed to treat spasticity of the lower extremities 6 months after his injury, but muscle spasm remained in thoracoabdominal region as a non-blocked area. He began to notice decreasing spasticity of the thoraco-abdominal muscles 14 months after the injury. He died of acute peritonitis 8 years after the injury.

Autopsy demonstrated that there was a large cystic cavity extending from T4 downwards L4. At T4 and T5 levels, several cavities and arachnoidal adhesions were identified. At the lower thoracic and lumbar levels there was a single, central smoothwalled cavity which was fairly central lying posteriorly to the central canal, and diffuse demyelination, gliosis of the posterior and post-lateral funiculi. In the upper thoracic cord, an original cavity in the glial scar was observed, and in the C8 segment the right posterior grey matter was rarefied.

In microangiographs, the capillaries in the dorsal grey matter and the anterior part of 

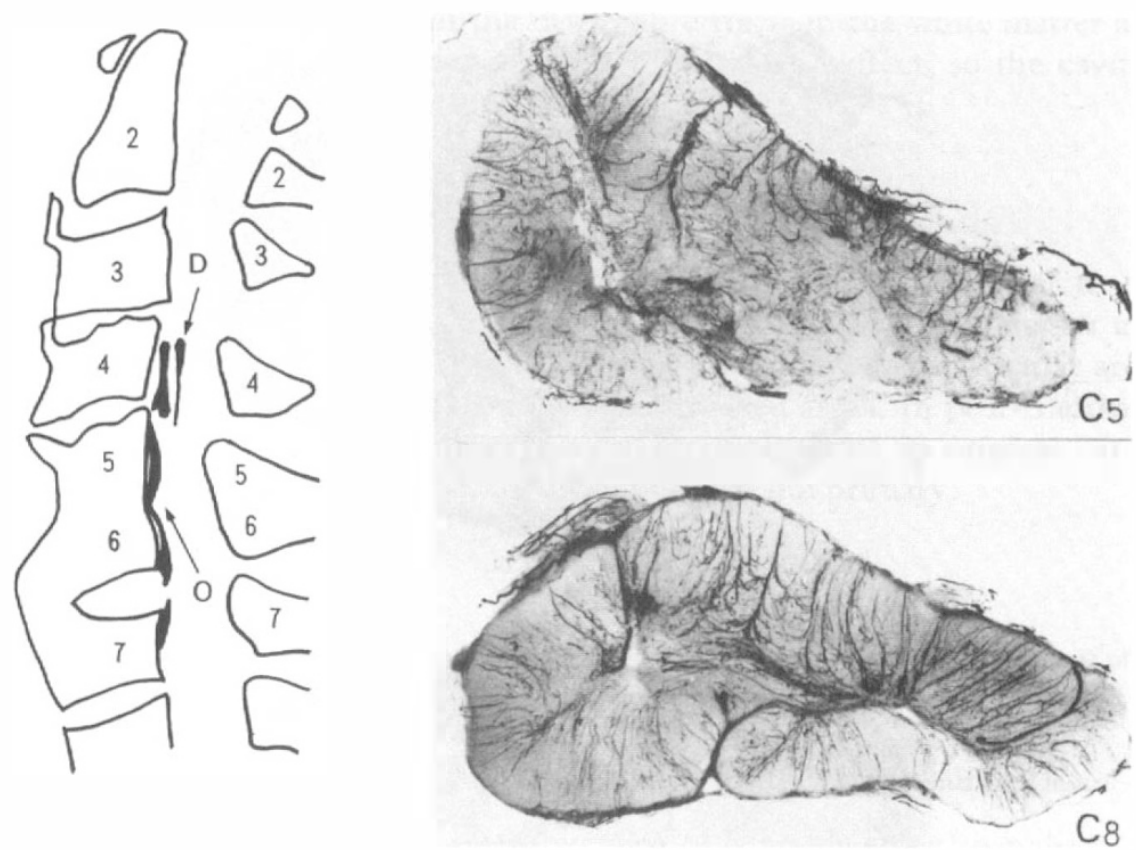

Figure 2 Case 13, myelopathy caused by OPLL. A Diagram from the preoperative radiogram. D: Ossification of dura matter, O: OPLL. B Microangiograms of transverse section $5 \mathrm{~mm}$ thick. In $\mathrm{C} 5$ level, the intrinsic arteries show an abnormal arrangement (Zone 3). In C8 level, the network in the grey matters disappears, the posterior perforating branches and central transverse branches appear to be increased (Zone 4 ).

the posterior columns disappeared (Zone 1). The central arteries were distorted by distending forces of the syrinx (Fig. 3B). In the original injured segments, capillaries showed an abnormally distorted arrangement (Zone 3) in the glial scars and filling defect (Zone 1) in the right dorsal grey matter (Fig. 3A).

Comment: The original cavity was observed in the upper thoracic cord. The posttraumatic syrinx extended below the level of the initial injury. The vascular network of the posterior grey matter disappeared and the central arteries were distorted by the distending forces of the syrinx.

\section{Discussion}

Many authors have documented microangiographic findings in experimental spinal cord injuries during the last quarter century.

Fairholm (1971) defined two zones in microangiographs 7 to 14 days after experimental spinal cord injury. Zone 1 was an area of non-filling, capillaries progressively lost their ability to conduct blood and necrosis of all elements including capillaries ensued. Zone 2 was the area of vascular filling with damaged neurons and axons. The presence of patent capillaries in Zone 2 provided the potential for recovery of those structures that survived the effects of the mechanical injury. Recovery of damaged neurons and axons depended upon a preserved microcirculation. The coexistence of damaged axons and neurons and normal appearing capillaries indicated that the microvasculature was relatively resistant to trauma. 


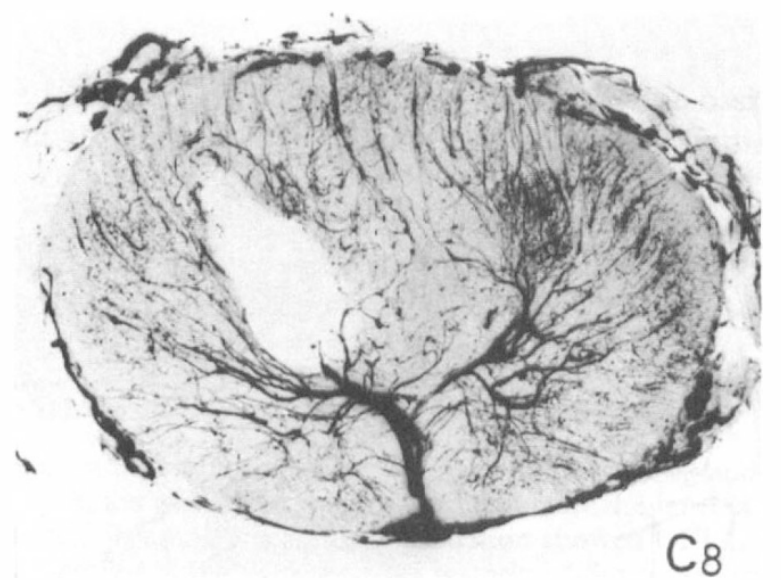

A

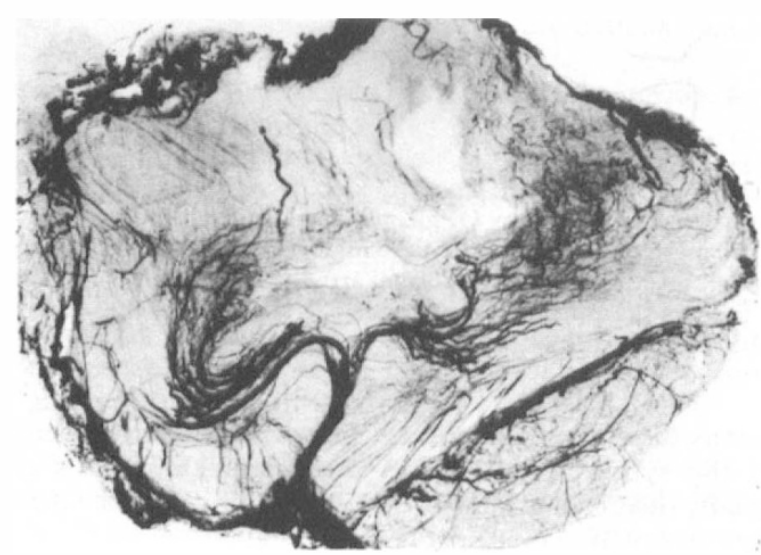

B

Figure 3 Case 14, post-traumatic syringomyelia. A Microangiogram of transverse sections $5 \mathrm{~mm}$ thick in C8 level. The vascular networks of the right posterior horn have disappeared. $\mathbf{B}$ Microangiogram in L1 levels. The central arteries are disterted by distending forces of the syrink.

We added Zone 3 and Zone 4 in the chronic stage of traumatic spinal cord injury and myelopathy, Zone 3 was the area of glial scar in which the capillaries showed an abnormally distorting arrangement. Zone 4 was a hypervascular area in patients with myelopathy.

Experimentally, Sako (1977) and Nakamura (1981) reported that, in acute injury, blood circulation was reduced, but in chronic compression, despite some deformation, there was no reduction of blood circulation.

We found hypervascular areas in a patient with myelopathy.

In post-traumatic syringomyelia, vascular factors which included initial central haemorrhage, central ischaemia and venous thrombosis might play a significant role in the origin of the myelomalic cores, but in cavity extension vascular factors were difficult to identify with any certainty. The mechanisms of extension of the post-traumatic syrinx was probably connected with changes in the pressure in venous system, as 'slosh and suck mechanisms' (Williams, 
1981). Barnett (1976) stated that the dense fibre tracts in the white matter and the anterior commissures presumably had a restraining effect, so the cavities tended to extend to the grey matter.

\section{Conclusion}

In traumatic cord injury, the areas of non-filling, were proportional to the injury force. They were usually found in the posterior central grey matter and the ventral posterior columns. In myelopathy, the reactive hypervascular areas were observed adjacent to the chronically compressed areas. In post-traumatic syringomyelia, vascular factors may play a significant role in original cavity formation, but in cavity extension, these factors were not primary.

\section{References}

BARNeTt HJM, JousSe AT 1976 Post-traumatic syringomyelia (cystic myelopathy). Handbook of Clinical Neurology 26, North-Holland Publishing Company, Amsterdam, pp 113-1571.

Crock HV, Yosizawa H 1977 The blood supply of the vertebral column and spinal cord in man. Springer Verlag, New York.

FAIRHOLM DJ, TÚRNBULL IM 1971 Microangiographic study of experimental spinal cord injuries. fournal of Neurology 35:277-286.

FRIED L, GOODKIN R 1971 Microangiographic observations of the experimentally traumatised spinal cord. Fournal of Neurosurgery 25:709-714.

FukUdA S, ChARLES BW 1972 Experimental cervical myelopathy: effects of compression and ischemia on the canine cervical cord. Fournal of Neurosurgery 37:631-652.

Griffiths ER, McCormick CC 1981 Post-traumatic Syringomyelia (Cystic Myelopathy). Paraplegia 19:81-88.

JELLING K 1976 Neuropathology of cord injuries. Handbook of Clinical Neurology 25, NorthHolland Publishing Company, Amsterdam, pp 43-121.

Kakulus B, BeDbrook GM 1976 Pathology of injuries of the vertebral column. Handbook of Clinical Neurology 25, North-Holland Publishing Company, Amsterdam, pp 27-42.

KinOSHITA H 1977 Early management of spinal cord injuries. Rinsho Seikei Geka 12:1045-1058.

MANNEN T 1963 The vascular lesions in the spinal cord in the aged. Rinsho-sinkei-gaku 3:47-63.

Nakamura K, Machida H, Tanaka H, et al. 1981 Experimental study of cervical spondylotic myelopathy-Spinal cord blood flow in cervical canal stenosis. Fournal of the fapanese Orthopaedic Association 55:747-754.

Ono K, Ota, H, Tada K, Yamamoto T 1977 Cervical myelopathy secondary to multiple spondylotic protrusions. A clinicopathologic Study. Spine 2: 109-125.

RANA NA, HANCOCK DO, TAYLAR AR, et al. 1973 Atlanto-axial subluxation in rheumatoid arthritis. Fournal of Bone and Surgery 55B:458-470.

Rossier AB, Foo D, Shilito J, et al. 1981 Progressive late post-traumatic syringomyelia. Paraplegia 19:96-97.

Sako T, Tomimura K, Maebara T, et al. 1977 Acute and chronic compression on the spinal cord and the response on the permeability of the microvasculature. An experimental study. Journal of the Japanese Orthopaedic Association 51:215-233.

Vernon JD, Chir B, Silver JR, Ohry A 1982, Post-traumatic syringomyelia. Paraplegia 20:339-364.

Watson N 1981 Ascending cystic degeneration of the cord after spinal cord injury. Paraplegia 19:89-95.

Williams B, Terry AF, Jones HWF, et al. 1981 Syringomyelia as a sequel to traumatic paraplegia. Paraplegia 19:67-80.

Wolman L 1965 The Neuropathology of traumatic paraplegia. Paraplegia 1:233-251. 